\title{
Efecto antimicrobiano in vivo de la infusión de Camellia sinensis sobre bacterias orales
}

\author{
In vivo antimicrobial effect of Camellia sinensis on oral bacteria
}

\begin{abstract}
Resumen
Con el objeto de determinar, el efecto antimicrobiano in vivo de la infusión de Camellia sinensis (Té verde), en forma de colutorio al $10 \%$; se colectó saliva no estimulada de 32 personas aparentemente sanas: 1) antes del enjuague, 2) inmediatamente después, y 3) luego a los 30 minutos. Las muestras se sembraron en Agar Tripticasa Soya y Agar Mitis Salivarius Bacitracina; para luego procederse al recuento de unidades formadoras de colonias de Estreptococos mutans por $\mathrm{ml}$. El análisis estadístico de los resultados, mediante las prueba " $\mathrm{t}$ " y Wilcoxon, indican que existen diferencias significativas entre los recuentos realizados. Por otro lado en el análisis del colutorio para determinar la presencia de polifenoles, mediante la espectrofotometría infrarroja se observó picos de transmitancia en longitudes de onda para los grupos oxidrilos $(-\mathrm{OH})$ y anillo aromático. Se concluye que hay una efectiva reducción en el recuento de microorganismos de la microflora mixta salival, y en el caso del recuento de los Estreptococos mutans, la disminución se aprecia significativa inmediatamente despues, manteniendo tal significancia en la lectura de los 30 minutos.
\end{abstract}

\section{Abstract}

In order to determine, in vivo antimicrobial effect of Camellia sinensis infusión (green Tea), as a mouthwash at $10 \%$; not stimulated saliva of 32 seemingly healthy people was collected: 1) Before mouthwash, 2) immediately after, and 3) after 30 minutes. The samples were spread in Agar Tripticasa Soy Bean and Agar Mitis Salivarius Bacitracina; then proceeded to the recount of the forming units of colonies of Mutans Streptococci for mL: The statistical analysis of results, by means of " $\mathrm{t}$ " and Wilcoxon tests, indicate that significant differences exists. On the other hand in the analysis of the mouthwash to determine polyphenols presence, by means of the infrared spectrophotometry peaks transmitted in wave lengths for the oxydril groups $(-0 \mathrm{H})$ and aromatic ring were observed. One concludes that there is an effective reduction in the number of microorganisms of the mixed salivary micro flora, and in case of the amount of colonies of Mutans Streptococci, the decrease is significantly appreciated immediately later, maintaining the same significance in the 30 minute results.

\section{Introducción}

La caries dental es aún el gran problema en la salud bucal en todas las latitudes mundo. En el Perú se notifica una prevalencia de $90 \%$ caries dental (Informe de diagnóstico situacional Facultad odontología UNMSM, 2006). El biofilm de la placa dental está íntimamente ligado a tal patología, siendo el Streptococcus mutans, el microorganismo más importante seguido por el Lactobacillus y el Actinomyces. ${ }^{1,2,3}$ De ahî que el control de los microorganismos relacionados con la placa dental, así como del proceso carioso, es de vital importancia para el control de la enfermedad, y uno de los mecanismos es el uso de antimicrobianos. ${ }^{4}$

La medicina natural, a partir de las plantas y sus propiedades antimi- crobianas, últimamente ha recibido mucha atención de los científicos, comprobando una series de propiedades de compuestos como los polifenoles, que van confirmando que permiten combatir a los agentes patógenos como el Staphylococcus aureus resistentes, ${ }^{5,6}$ y adicionalmente a otras bacterias bucales como S. mutans ${ }^{7,8}$, y Porphyromomas gingivalis, referido por Okamoto; ; así como la actividad enzimática proteinica importante que afecta los tejidos periodontales ${ }^{10}$.

Las ventajas son diversas: fácil acceso, bajo costo y sobre todo pocos efectos colaterales indeseables.

En el Té, especialmente el verde y el blanco, la presencia de taninos que inhibe la síntesis del dextran ${ }^{11}$ el fluor que inhibe al acción enzimático,

\section{Hilda Moromi Nakata', Elba Martínez Cadillo', Margot Gutiérrez llave², Donald Ramos Perfecto ${ }^{1}$, María E. Núñez Lizarraga ${ }^{3}$, Jonny Burga Sánchez ${ }^{1}$, Javier Tello ${ }^{4}$, Isabel Trevejo ${ }^{5}$}

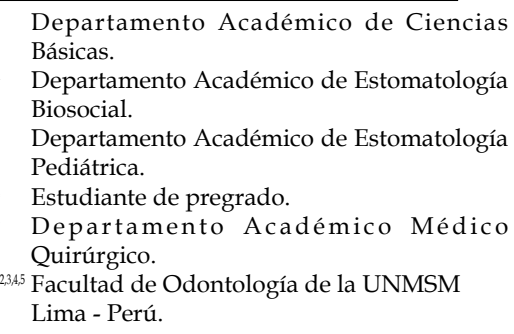

Correspondencia:

Mg. Hilda Moromi Nakata

Facultad Odontología, UNMSM

Av. Amezaga s/n, Lima 1 Perú.

Tlf: 6197000/3410

e-mail: hmoromin@unmsm.edu.pe

Palabras clave: Saliva. Camellia sinensis. Infusión. Colutorio. Estreptococos mutans. Espectroscopia Infrarroja.

Key words: Saliva. Camellia sinensis. Infusión. Mouthwash. Mutans Streptococci. Infrared spectroscopy así como los flavonoides que inhibe la adherencia, la inhibición de la producción de ácido láctico ${ }^{12}$ por los extractos, entre otros, confieren efecto inhibitorio en el desarrollo del $S$. mutans, y también sobre los hongos, conocimientos que han propiciado la adición de los extractos en algunas pastas dentales. ${ }^{13}$

En los últimos años se ha incrementado notoriamente los estudios, mayormente in vitro, de sustancias naturales, entre ellas el Té, especialmente el verde hallándosele una serie de propiedades antimicrobianas y anticancerígenos, entre otras. A tal punto que la Sociedad Americana de Microbiología, en su encuentro del 2004 con los investigadores de la Universidad de Pace de Nueva York, concluyen que los ex- 
tractos de té verde matan las bacterias y que por tal característica ya puede ser incluido dentro de las alternativas para la higiene oral. Concepto que es concordante con las observaciones de otros investigadores como $\mathrm{Wu}$, quien ha realizado valiosos estudios sobre esta materia. ${ }^{14}$ Un estudio antecedente al presente son los hallazgos in vitro realizadas por Moromi (Moromi NH, y cols en Prensa).

Los estudios in vivo con la modalidad de infusión como colutorio tiene limitaciones bibliográficas por lo que aún es desconocido.

En concordancia con tales consideraciones, el objeto de la investigación, fue demostrar el efecto antimicrobiano in vivo, de la infusión del té verde sobre microorganismos de la flora salival y estreptococos mutans

\section{Materiales y Método}

Población del estudio: se utilizaron muestras salivales de 32 estudiantes, 24 de sexo masculino y 8 del femenino de la Facultad de Odontología de la Universidad Nacional Mayor de San Marcos, previo consentimiento informado de cada participante.

Colutorio en estudio: para el estudio se preparó una infusión al $10 \%$, con $10 \mathrm{~g}$ de Té verde (envasado comercialmente) en $100 \mathrm{ml}$ de agua hervida expuesta por tres minutos.

Colección de muestras: el material de estudio provino de las muestras de saliva de los estudiantes, colectadas en recipientes estériles, y distribuidos de acuerdo al siguiente arreglo procedimental:

Muestra A: Saliva antes del uso con el colutorio

Muestra B: Saliva inmediatamente después del uso del colutorio, por un minuto.

Muestra C: Saliva 30 minutos después del uso del colutorio.

Procesamiento de las muestras: para el caso del recuento total de bacterias, cada muestra fue sembrada en Agar Tripticasa Soya (TSA), en diluciones sucesivas al décimo, para lograr el recuento de Unidades Formadoras de colonias por $\mathrm{ml}$ (UFC/mL), e incubadas aerobiosis a $37^{\circ} \mathrm{C}$, por 24 - 48 horas.

En tanto que para el caso del recuento de Estreptococos mutans, se usó un grupo al azar, de 12 muestras, procesadas en Agar Mitis Salivarius Bacitracina (AMSB), incubadas en $\mathrm{CO}_{2}$, a $37^{\circ} \mathrm{C}$, por $48-72$ horas.

Análisis químico del Té verde: para la determinación de la presencia de polifenoles en la infusión, se utilizó el método de la Espectrofotometría infrarroja con transformación de Fourier
(FT-IR), realizado en el servicio USAQ de la Facultad de Química e Ingeniería Química de la Universidad Nacional Mayor de San Marcos.

\section{Resultados}

Los resultados sobre las bacterias totales se muestran en el Cuadro 1 y Figs 1 y 2. La Prueba $\mathrm{t}(\mathrm{t}=4,754)$ resultó significativa a nivel del $99 \%$ en los re- sultados inmediatamente después del enjuague; así como también $(\mathrm{t}=3.114)$ a los 30 minutos después. La prueba de Wilcoxon ha confirmado los hallazgos de la prueba $t$, aceptándose el efecto benéfico del colutorio en la reducción del recuento total de microorganismos ocurrido inmediatamente después de su empleo y con efecto aún activo hacia los 30 minutos después del empleo del colutorio.

\section{Cuadro 1. Recuento total de bacterias en Agar Tripticasa Soya colectadas en saliva luego del uso de la infusión del Té verde}

\begin{tabular}{lccc}
\hline & \multicolumn{3}{c}{ Unidades formadoras de colonias / ml } \\
\cline { 2 - 4 } Muestra & Antes & $\begin{array}{c}\text { Inmediatamente } \\
\text { Después }\end{array}$ & 30 minutos después \\
\cline { 2 - 4 } Promedio & 16648062,5 & 12831250 & 9743750 \\
D.S & 7332722,0 & 7410658,3 & 7493762,5 \\
\hline
\end{tabular}

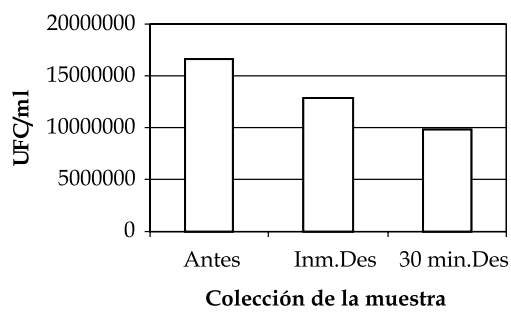

Fig 1, Recuento total de bacterias en Agar Tripticasa Soya colectadas en saliva luego del uso de la infusión del Té verde.

Los resultados sobre el grupo de Estreptococos mutans se aprecian en el Cuadro 2 y Figs 3 y 4 . La prueba de Wilcoxon ha confirmado los hallazgos encontrados con la prueba $t$, aceptándose el efecto benéfico del colutorio

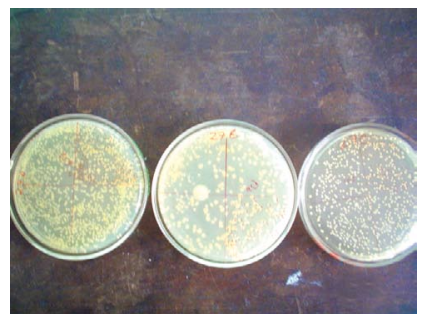

Fig 2. Colonias de bacterias totales en Agar Tripticasa Soya.

en la reducción del recuento total de microorganismos ocurrido inmediatamente después de su empleo y con efecto aún activo hacia los 30 minutos después del empleo del colutorio.

Cuadro 2. Recuento de Estreptococos mutans en Agar Mitis Salivarius Bacitracina colectadas en saliva luego del uso de la infusión del Té verde

\begin{tabular}{cccc}
\hline & \multicolumn{3}{c}{ Unidades formadoras de colonias / ml } \\
\cline { 2 - 4 } Muestra & Antes & $\begin{array}{c}\text { Inmediatamente } \\
\text { después }\end{array}$ & 30 minutos después \\
Promedio & 32591,7 & 14758,3 & 14614,2 \\
D.S & 28393,7 & 11550,8 & 26168,7 \\
\hline
\end{tabular}

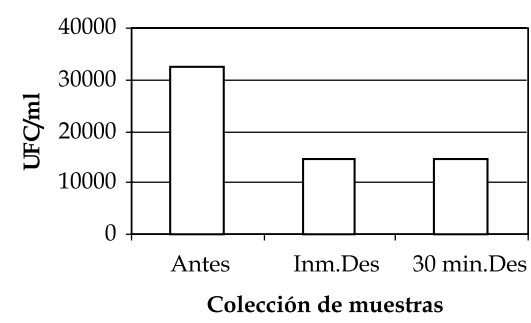

Fig 3. Recuento de Estreptococos mutans en Agar Mitis Salivarius Bacitracina colectadas en saliva luego del uso de la infusión del té verde.

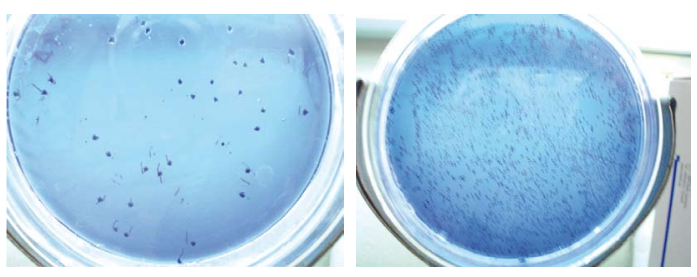

Fig 4. Colonias de Estreptococos mutans en Agar Mitis Salivarius Bacitracina. 
Los resultados de la determinación de la presencia de polifenoles en la infusión, mediante la Espectroscopia Infrarroja con transformación de Fourier (FT-IR) se muestran en la Fig 5.

\section{Discusión}

Los efectos antimicrobianos para el control de microorganismos orales mediante sustancias naturales, se estudia desde décadas anteriores ${ }^{15}$ cobrando cada vez una mayor atención, especialmente en lo referente a la acción de los polifenoles (catequinas), presentes en productos como el Té y sus variedades: verde, negro, etc; cuyas cuantías difieren por los particulares procesamientos antes del expendio al público.

Existen diversos mecanismos por los cuales el Té verde produce acción sobre las bacterias, entre ellas, la inhibición de la producción de ácidos y de la enzima glucosiltransferasa. ${ }^{16}$

La mayoría de los polifenoles en el Té verde son flavonoides, comúnmente conocidos como catequinas. Las principales catequinas son: (-)-epicatechin, (-)-epicatechin-3-gallate, (-)-epigallocatechin, y (-)-epigallocatechin-3gallate. ${ }^{17}$

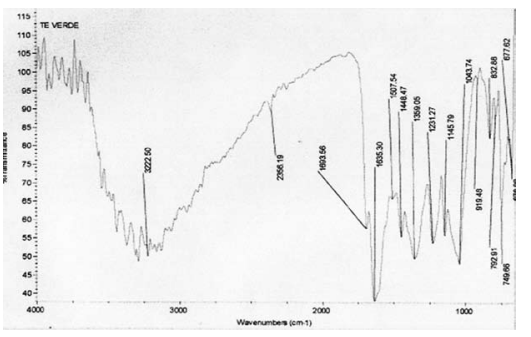

Fig 5. Espectroscopia Infrarroja con transformada de Fourier de la muestra de infusión de Camellia sinensis.

Por otro lado, están las diferentes opciones o preparaciones para el uso del Té: 1) como simple infusión, 2) luego de un tiempo de hervido, y 3) como extracto luego de un proceso químico. En este sentido el presente estudio, que utilizó la primera modalidad, no se puede comparar, dado que no se ha podido hallar de estudios similares. Pueden existir, y la investigación en este sentido sufre de tal limitación.

El primer estudio que se realizó in vitro, (Moromi NH, y cols. En Prensa) ha permitido vislumbrar las bondades del Té verde, y en conjunto con los resultados de esta investigación subsiguiente, válida y confiable, son bastante sugerentes para sugerir el planteamiento de otros esfuerzos que cimienten y promuevan una tecnología tan simple y elemental y de costo extremadamente mínimo, como el uso de una infusión mediante enjuagatorio para controlar y prevenir las nosologías bucales de origen bacteriano. Se sugiere otros diseños procedimentales para averiguar los efectos de: otras concentraciones, otras frecuencias de uso, precisiones de efectividad específica antibacteriana, comparaciones con colutorios químicos del ámbito comercial, etc.

Al término de la investigación se llegó a las siguientes conclusiones.

1. El colutorio de la infusión empleado ha mostrado efectividad en la reducción del recuento de las bacterias orales, tanto al registro inmediato a su empleo como también al registro luego de los 30 minutos de utilización.

2. En el caso del Estreptococos mutans la disminución efectiva inmediatamente después del enjuague, se mantiene además en el registro de los 30 minutos.

\section{Agradecimiento}

Al Consejo Superior Investigación de la Universidad Nacional Mayor de San Marcos por la financiación del presente estudio cuyo código es 060501071

\section{Referencias bibliográficas}

1. Ministerio de Salud del Perú: "Plan de Salud Bucal 2005" http:/ / www.minsa. gob.pe/portal/campanas/SBucal/ Archivos/RM538-2005\%20Plan\%20de \%20Salud\%20Bucal.pdf

2. www.msnbc.msn.com/id/3079355/ prin/1/displaymode/1098/

3. Negroni M. Microbiología estomatológica. Argentina: Edit. Panamericana. 1999:223-225.

4. Negroni M. Microbiología estomatológica. Argentina: Edit. Panamericana. 1999:237

5. Newson SWB. MRSA: Past, present, future. Journal of Royal Society of Medicine London. 2004;97:509.

6. Dryden MS, Dailly S, Crouch M. A ramdomised, controlled trial of tea tree tropical preparations versus a standard tropical regime for the clearance of MRSA colonization. J. Hosp Infect. 2004;54:283-6.
7. Rasheed A, Haider M. Antibacterial activity of Camellia sinensis extracts against dental caries Arch. Pharm Res 1998 Jun 21 (3):348-52.

8. Otake S, Makimura M, Kuroki T, Nishihara Y, Hirasawa M. Anticaries effects of polyphenolic compounds from Japanese green team. Caries Res (Switzerland) 1991;25(6):438-43.

9. Okamoto $\mathrm{M}$, Leung $\mathrm{KP}$, Ansai $\mathrm{T}$, Sugimoto A, Maeda N. Inhibitory effects of green tea catechins on protein tyrosine phosphatase in Prevotella intermedia. Oral Microbiol Inmunol. 2003;18:192-195.

10. Okamoto M, Sugimoto A, Leung KP, Kakayama K, Kamaguchi A, Maeda N. Inhibitory effect of green tea catechins on cysteine proteinases in Porhyromonas gingivalis. Oral Microbiol Inmunol. 2004;19:118-120

11.S. Rosen M, Elvi-Lewis FM, Beck EX. Anticariogenic effects of tea in rats. J. Dent. Res. 1984;63(5):658-660.

12. Koompirojn K, Guay M, Peawchana W, Suesuwan A, Ingkasate. A Inhibition of lactic and poysaccharide formation of Streptococcus mutans by tea extract in Vitro. CU Dent J 2001;24:195-202.

13. Anónimo. Bacteriology; white tea has an inhibitory effect of various pathogenic bacteria. Obesity: Fitness \& Wellness Weeks Atlanta. 2004;Aug 26: 86

14. Didier PH. Green Tea Health Benefits. www.green-tea.dminternational.biz// ky-green-tea-health-html

15. Moromi NH, Martinez CE, Villavicencio GJ, Burga SJ y Ramos PD, Efecto antimicrobiano in vitro de Camellia sinensis sobre bacterias orales. Odontol Sanmarquina 2007; 10 (1)-18-20

16. Saeki Y, Ito Y, Shibata M, Sato Y, Okuda K, Takazoe I. Bull Tokio dent. Coll. 1989; 30(3):129-135

17. Tagashira M, Uchiyama K, Yoshimura T, Shirota M, Uemitsu N. Inhibition by hop bract polyphenols of cellular adherence and water-insoluble glucan synthesis of mutans streptococci. Biosci Biotechnol Biochem 1997;61(2):332-335.

18. Mukhtar H, Ahmad N. Tea polyphenols: prevention of cancer and optimizing health. Am J Clin Nut. 2000;71(6):1698 1702.

Recibido :18-04-2007

Aceptado para publicación: 05-11-2007 